Original Research Paper

\title{
Impact of Business Intelligence Competencies on the Organizational Capabilities in Jordanian Banks
}

\author{
Mohammad Atwah Al-Maaitah \\ Al-Balqa' Applied University, Jordan
}

Article history

Received: 29-04-2018

Revised: 09-06-2018

Accepted: 16-08-2018

Email: dr.maaitah@gmail.com

\begin{abstract}
This study aims to identify the role of business intelligence competencies (Managerial competencies, Technical competencies and cultural competencies) on the organizational capabilities in Jordanian banks (process improvement, innovations, flexibility, agility). Hence, a questionnaire was used to gather data to achieve the purpose of this study. Since it is difficult to cover the total population, a convenient sample was used. Therefore, 385 questionnaires were distributed and 340 were retrieved, 320 of which were suitable for analysis. Structural equation modeling via PLS3 was used to analyze the data. The findings from this study show that the level of availability of Business Intelligence competencies and organizational capabilities in Jordanian banks were medium. The core conclusion of this study proves that business intelligence competencies have a significant impact on the organizational capabilities in Jordanian banks. The main recommendation of this study was to continually assess the efficiency of business intelligence competencies in Jordanian commercial banks in order to develop them in line with the changing environment and new business requirements.
\end{abstract}

Keywords: Managerial Competencies, Technical Competencies, Cultural Competencies, Flexibility, Agility

\section{Introduction}

Today, information technology has assumed great importance because it is the starting point for innovations and success in organizations. Business Intelligence tools are new technologies that have important effect on all organization aspects. So, organizations have to pay attention to the Business Intelligence Competences. Business Intelligence with fewer competencies will not attain its objective. And, to use these tools in an effective way, some competencies must be available to produce business intelligence services and programs and use them to make decisions efficiently and effectively. All organizations seek to enhance their capabilities by using new strategies, techniques and technology, as they have realized that meeting customer needs and being responsive to internal and external circumstances would be their drivers to obtain and maintain competitive advantage. So, all organizations are seeking to acquire new technology to increase their capabilities. We note that some companies adopted the tools of business intelligence and some did not give any attention. This study is intended to identify the impact of business intelligence competencies (managerial, technical and cultural) on the organizational capabilities in Jordanian banks.

\section{General Background}

\section{Business Intelligence Competencies}

In the last few decades, companies and institutions of all sizes have become interested in the concept of business intelligence because it plays a great role in making rational decisions in a timely manner, especially in light of the great competition and globalization. These companies have to adopt new systems that help them identify customer needs and desires, as well as analysis of data and the extraction of reports necessary to work; in addition to monitoring the work performance (Rouhani et al., 2016). Business intelligence systems are responsible for creating effective knowledge and information to help decision makers and strategic leaders in their tasks (Olszak and Ziemba, 2004). Recently, organizations have started seeking new tools that assist analyzing large amounts of data from different resources (Olszak and Ziemba, 2007). Prior researchers (Kumar, 2013; Al-ma'aitah, 2013; Muhammad et al., 2014) listed many tools, such as Data Warehousing, Data Mining, Extraction Transformation Load (ETL) and On-Line Analytical Processing (OLAP), which are integrating to implement a comprehensive BI system as shown in Fig. 1. 


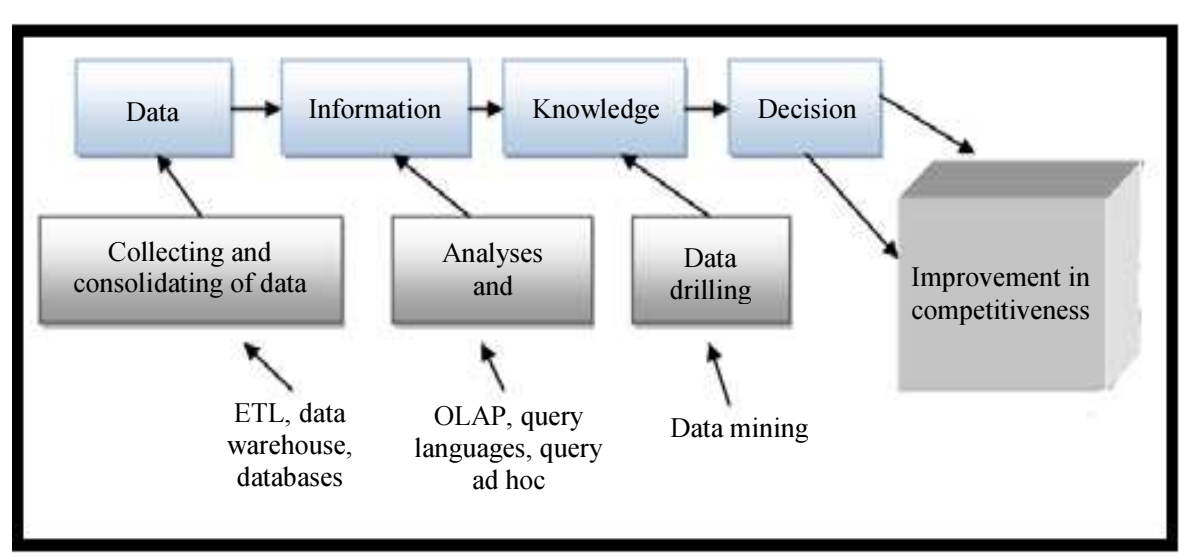

Fig. 1: Business Intelligence

Rouhani et al. (2016) Argued that business owners must employ further suitable BI tools to attain more realistic advantages. Ramakrishnan et al. (2012) confirmed that businesses work in a turbulent environment and BI systems help these businesses in supporting decision making and enhancing performance through dealing with huge amount of information and achieving competitive advantages. Prior researches prove that businesses should take into consideration some aspects before applying BI systems, such as organizational strategy, structure, culture and process (Arefin et al., 2015). Up to date researches have recommended that a BI system enhances business performance through information provided and used by managers (Cui et al., 2007). Sangari and Razmi (2015) asserted that there are competences for business intelligence's success and he divided them into three dimensions: Managerial competences, cultural competences and technical competences. In addition, he defined BI competences as the ability of the organization to produce business intelligence services and programs and to use them to make decisions efficiently and effectively.

\section{Organizational Capabilities}

Organizational capabilities indicate a company's ability to execute a range of tasks, taking advantage of organizational resources (Carmeli and Tishler, 2004). Moreover, Hwang (2011) argued that organizational capabilities are qualifications that guide organizations to do better than their competitors using modern business tools. So, organizations should enhance and manage their capabilities to increase organizational performance and market share.

Verona (1999) Divided organizational capabilities into four types: Technological, which refers to R\&D and manufacturing; external integrative, such as culture and absorptive structure; internal integrative, such as culture and integrative structures; and marketing capabilities, such as marketing mix policies. Some researchers focus on two areas of organizational capabilities: Exploration and exploitation. Exploration focuses on exploring new knowledge about organization opportunities, while exploitation focus on innovative methods of learning McGrath (2001). Wang and Ang (2004) described organizational capabilities using three items: Cost leadership, quality and innovation, which have an effect on competition.

Hwang (2011) confirms that firms can increase their capabilities like cross-functional coordination, information access, process improvement, innovativeness, flexibility and agility by using information technology. So, through successful BI implementation, firms can increase their capabilities. For the purpose of this research, we will refer to organizational capabilities through process improvement, innovativeness, flexibility and agility. And we will investigate how Business Intelligence Competencies will impact these capabilities.

\section{Literature Review}

Recently, explosion of the data has become a key concern in information technology; for example, WallMart conducts more than one million bargains per hour (David, 2012). So, business intelligence will play an important role in dealing with such huge amounts of data. David (2012) refers to BI as processes, technologies and tools required to achieve an action plan through transforming data to information and information to knowledge. Prior researchers studied BI from many aspects. Ramamurthy et al. (2008) Supports a comprehensive model about organizational factors which affect BI adoption. Hayen et al. (2007) provided that organizational, technical and project management capabilities are factors that have important roles in BI's success. White (2006) refers that BI application could be used at all organizational levels (operational, tactical and strategic). Ahmad (2015) assured that many of the strategic management studies refer to BI as a competitive key and he explored the relationship between employing effective BI and sustaining 
competitive advantages. Arefin et al. (2015) Argued that BI effectiveness and organizational effectiveness are affected by many organizational factors, such as strategy and structure. In addition, they provide that deploying a successful BI mediates the relationship between the organizational factors and organizational effectiveness. Moreover, Al-ma'aitah (2013) indicted that BI tools have a vital role in the decision-making process and enhancing organizational effectiveness. Williams and Williams (2007) argued that BI tools play an important role in knowledge discovery. Furthermore, knowledge sharing is affected by OLAP, data mining and data warehousing positively (Zabadi et al., 2015).

Rouhani et al. (2016) Asserted that BI functions have a significant impact on organizations' benefits and outcomes. Finally, Muhammad et al. (2014) confirmed that BI tools could help financial sectors to improve their services and get sustainability by adapting to rapidly changing environment. On the other hand, many previous studies have addressed the concept of organizational capabilities from many aspects. Pandey et al. (2018) indicated that availability of organizational capabilities, especially infrastructure, will lead to knowledge management process successfully. Also, he pointed out that the relationship between the two concepts is interchangeable. Rahman and Carpano (2017) suggested a framework linkage between governance system with organizational capabilities and performance.

Tuan and Takahasi (2010) applied their study on 120 firms in Vietnam and proved that there are strong relationships between organizational capabilities, performance and competitive advantages.

Hwang (2011) assured that adoption of an ERP system in organizations has a significant effect on business strategy and organizational capabilities. In addition, adopting an ERP system will lead firms to achieve superior levels of economic performance. Löfsten (2016) studied the use of modern technology in firms and its relevance to organizational capabilities. The findings proved that there is a significant relationship and it helped firms' long-term survival.

\section{Research Model and Hypotheses}

Depending on the previous literature, the research model (Fig. 2) supposes that business intelligence competencies will affect the organizational capabilities in Jordanian banks.

In the following paragraphs, there is more explanation about the research model elements and hypotheses.

\section{Managerial Competences}

Sangari and Razmi (2015) Defined managerial competences as the adequacy of an organization to establish information and knowledge relevant to its work in order to enhance its decision-making processes. So, to accomplish this objective, organizations should possess a set of clear procedures and methods to collect information and knowledge about their external environment on an ongoing basis as well as provide clear procedures and methods for effective knowledge and information dissemination and analyzing results. Lonnqvist and Pirttimaki (2006; Petrini and Pozzebon, 2009) have defined it as the efficiency and effectiveness of the organization to create unique knowledge which could help it make decisions and learn excellence from other organizations in the same field. Lonnqvist and Pirttimaki (2006) emphasized the importance of access to timely and effective information, not only for excellence and success, but also for survival. He also emphasized that managerial competencies have important roles in achieving business intelligence system strategies. Temtime and Pansiri (2005) Confirmed that managerial competences have important implications on organizational flexibility.

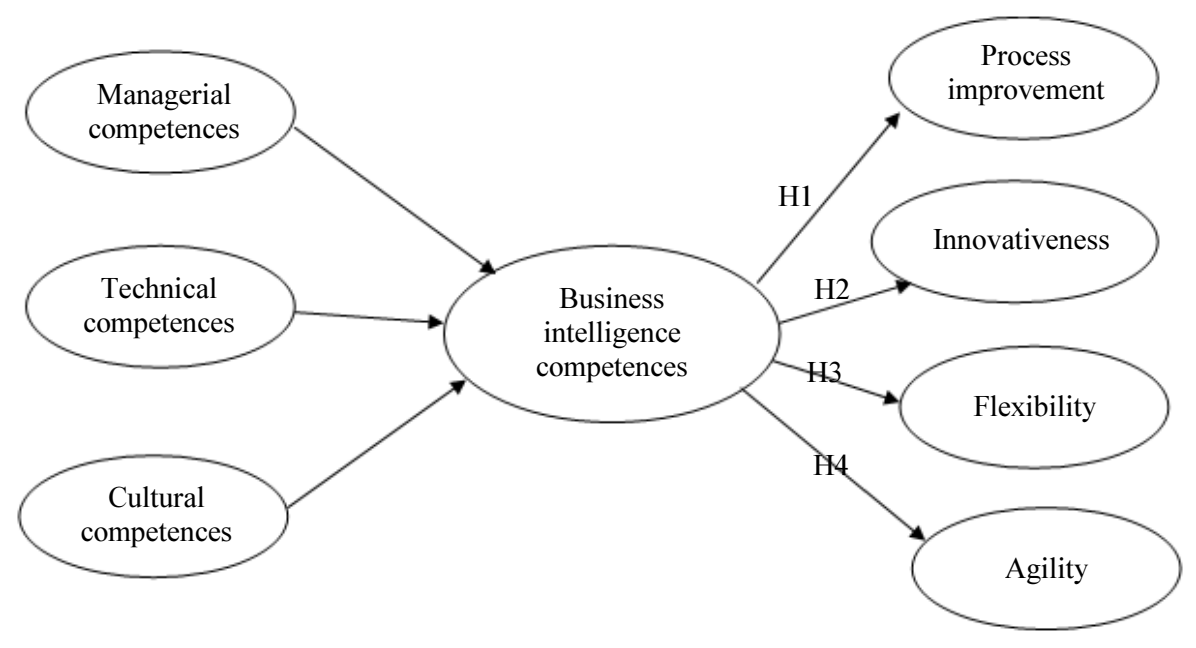

Fig. 2: The model of research 


\section{Technical Competences}

Petrini and Pozzebon (2009) referred to it as the ability of the organization to provide business intelligence software and optimize their applications for storing historical data and making online analysis processes. This dimension refers that an organization should have the appropriate software to analyze and categorize the data which is needed by the individuals and decision makers. Moreover, the results should be represented graphically to make them easy to understand. The organization should also have a dedicated database to assist decision-makers in developing strategies based on analyzing customer trends as well as applying different models to predict the future behavior of the organization's customers by using data mining techniques. Also, he referred that technical skills play an important role in applying knowledge management processes in an organization.

\section{Cultural Competences}

Sangari and Razmi (2015) defined it as the organization's ability to develop a culture of information gathering in an effective and efficient way. Machuca and Costa (2012) defines it as the organization's ability to develop a strong and powerful business intelligence culture in internal and external processes and to disseminate the culture of using business intelligence tools for greater benefit. Al-ma'aitah (2013) emphasized the importance of shared understanding and belief in the importance of business intelligence tools and the added value that can be gained from applying these tools in work and the importance of considering it as a strategic asset of the organization.

\section{Process Improvement}

Ravichandran and Rai (2000) defined it as a collection of actions to define, analyze and improve the processes in the organization to achieve the objectives and purposes of the organization. In addition, they contribute that processes improvement is high related to information system field and organizations which will adopt new technology will achieve process improvement. Coskun et al. (2008) argued that using information technology and applying new techniques on data help organization in process improvement, such as reducing cycle time, cycle cost, reduced delay in delivery, accomplishing activities, reduced paperwork and developing new services and products.

Eicker et al. (2008) argued that organizations must focus on their core competencies, which are appreciably affected by the skills and the knowledge of their workers, because it will lead to improve process management. Golfarelli et al. (2004) refers that BI that includes useful data warehouse improves operational processes and company strategy. Tellez (2015) Indicated that improved customer and employee satisfaction is affected by cultural competences.
H1: Business Intelligence Competencies has a Significant Impact on the Process Improvement.

\section{Innovativeness}

Koufteros (1995) defined it as the extent to which an organization is capable of improving their product quality, characteristic and performance. Organizations should launch their products and services at lower cost and in an efficient way. So, they are forced to use new techniques. Business intelligence systems help organizations identify customer needs (Turban, 2010). In addition, they help in designing and developing more cost-effective products and services.

Woszczyna (2014) found that human capital and competencies of both managers and employees are important factors for managing innovation in organizations. Farhadfar and Abtahi (2014) argued that management of innovation and technical competences are related. Woszczyna (2014) said that cultural competences may be a vital element of innovative activity.

H2: Business Intelligence Competencies has a Significant Impact on Organization Innovativeness.

\section{Flexibility}

Narasimhan et al. (2004) defined it as to what extent an organization could be faced with the needs of the customers without more costs, time and organizational trouble. Turban (2010) illustrate that BI and decision support systems could support organizations to be more flexible and meet all environmental factors. Flexibility in products and services enhance organizations' competitive advantages and increase market shares (Sanchez, 1995). To enhance organization flexibility, organizations should depend on information technology in all their activities. Temtime and Pansiri (2005) Confirmed that Managerial Competences have important implications for Organizational Flexibility. GhalichKhania and Hakkakb (2016) Proved that BI applications have significant effect on flexibility and agility by enhancing decision-making process and supporting organizations in reacting to the rapidly changing environment. Ngo and Loi (2008) referred that market flexibility and outcome are affected by culture.

H3: Business Intelligence Competencies has a Significant Impact on Organization flexibility.

\section{Agility}

Lee (2004) defined it as to what extent an organization adapts to a continuously shifting and irregular business environment, so that it can survive and take advantage of changes and opportunities. Coronado et al. (2002) Confirmed that Information Technology is an essential element of agility. Turban (2010) support that BI and decision support system play an important role in achieving organizational agility. Sangari and Razmi (2015) provided that managerial competence, technical 
competence and cultural competence are key enablers of organization agility and performance.

H4: Business Intelligence Competencies has a Significant Impact on Organization agility.

\section{The Measurement}

In this research, measures and constructs were adapted from related studies to achieve the study's intention. Table 1 describes the study constructs.

\section{Instrument Development}

A questionnaire was used to gather data to achieve the purpose of the study. The questionnaire was adopted from previous studies and it was modified when required. A total of thirty-two (32) items were developed, as shown in Table 1. The constructs of business intelligence competencies were adopted from (Sangari and Razmi, 2015), while organization capabilities construct was adopted from (Hwang, 2011). The questionnaire was presented to 7 arbitrators in the field of information systems. All comments were taken into consideration to modify the questionnaire.

\section{Sampling and Questionnaire Distribution}

The sample of the study consisted of the directors, their deputies, their assistants and the heads of the departments in the Jordanian commercial banks. Since the whole population is complicated to determine, a convenient sample has been used. Therefore, 385 questionnaires were distributed and 340 were retrieved, 320 of which were valid for analysis.

Table 1: Study Instruments

\begin{tabular}{|c|c|c|}
\hline Construct & Code & Measurement Item \\
\hline Business Intelligence Competencies & BIC & \\
\hline \multirow[t]{10}{*}{ Managerial Competences (MC) } & MC1 & $\begin{array}{l}\text { The Bank's procedures and methods have been well defined to consistently gather } \\
\text { knowledge and information about customer trends, services and competitors. }\end{array}$ \\
\hline & $\mathrm{MC} 2$ & $\begin{array}{l}\text { The Bank's procedures and methods have been well defined to consistently collect, } \\
\text { manipulate, store and distribute knowledge and information. }\end{array}$ \\
\hline & MC3 & $\begin{array}{l}\text { The Bank's procedures and methods have been well defined to consistently analyze } \\
\text { knowledge and information. }\end{array}$ \\
\hline & MC4 & $\begin{array}{l}\text { The Bank's procedures and methods have been well defined to ensure easy and } \\
\text { timely access to required knowledge and information. }\end{array}$ \\
\hline & MC5 & Decisions are taken depending on accurate, valid and credible information. \\
\hline & TC1 & The Bank has a data warehouse to store historical data. \\
\hline & $\mathrm{TC} 2$ & $\begin{array}{l}\text { The Bank uses effective and appropriate technological tools to support data } \\
\text { integration and analysis. }\end{array}$ \\
\hline & TC3 & $\begin{array}{l}\text { The Bank uses effective and appropriate technological tools to support } \\
\text { information distribution and dissemination. }\end{array}$ \\
\hline & TC4 & The Bank has computerized decision support systems that assist in decision-making. \\
\hline & TC5 & The bank has data mining tools to explore hidden relations. \\
\hline \multirow[t]{5}{*}{ Cultural Competences (CC) } & $\mathrm{CC} 1$ & Knowledge and information are used effectively in all aspects of the Bank's business. \\
\hline & $\mathrm{CC} 2$ & $\begin{array}{l}\text { Bank management recognizes the value of information and knowledge in achieving } \\
\text { competitive advantage. }\end{array}$ \\
\hline & $\mathrm{CC} 3$ & The Bank's management considers information and knowledge as strategic assets. \\
\hline & $\mathrm{CC} 4$ & $\begin{array}{l}\text { The Bank's management is interested in sharing information and knowledge } \\
\text { with business partners. }\end{array}$ \\
\hline & CC5 & The Bank shares business partners and customers in decision-making. \\
\hline Organizational Capabilities & $\mathrm{OC}$ & \\
\hline \multirow[t]{4}{*}{ Process Improvement (PI) } & PI1 & The bank is able to reduce new services evolution cycle times. \\
\hline & $\mathrm{PI} 2$ & The bank is able to reduce delays in transaction processing. \\
\hline & $\mathrm{PI} 3$ & The bank is able to reduce of using paperwork. \\
\hline & PI4 & The bank is able to reduce transaction costs. \\
\hline \multirow[t]{4}{*}{ Innovativeness (IN) } & IN1 & The bank is able to establish new services with unique features. \\
\hline & IN2 & The bank is able to enhance service quality. \\
\hline & IN3 & The bank is able to promote services with superior performance. \\
\hline & IN4 & The Bank's management encourages research and development. \\
\hline \multirow[t]{4}{*}{ Flexibility (FL) } & FL1 & The bank is able to change services design according customer needs. \\
\hline & FL2 & The bank is able to change services volume according customer needs. \\
\hline & FL3 & The bank is able to change services design without exaggerated cost. \\
\hline & FL4 & The bank is able to change services volume without exaggerated cost. \\
\hline \multirow[t]{4}{*}{ Agility (AG) } & AG1 & The bank is able to quickly respond to emerging environmental opportunities. \\
\hline & AG2 & The bank is able to quickly respond to emerging natural threats. \\
\hline & AG3 & The bank is able to quickly respond to competitors' actions. \\
\hline & AG4 & The bank is able to quickly respond to the internal problems. \\
\hline
\end{tabular}




\section{Data Analysis and Results}

For the purpose of testing the hypotheses of the study and to ensure the fitness of the model we will use PLS software. So, there are two steps that should be conducted to analyze PLS model (Hair et al., 2006). Firstly, we evaluate the reliability and validity of the model constructs. Second, we evaluate the structural model by interpreting the path coefficients and determining the sufficiency of the study model. The following sections show both of these two steps.

\section{Measurement Model Results}

In the beginning, factor loadings were investigated for all constructs to determine discriminant validity; the result was accepted for all constructs because its passed the cut-off value, 0.5 as suggested by (Hair et al., 2006) as shown in Fig. 3. So, the model constructs of this study achieve good convergent validity except item (CC3) whose loading was (0.449) and will be dropped and not included in the next step of the analysis.

Moreover, composite reliability, AVE and Cronbach's alphas of the constructs were investigated to measure the convergent validity as proposed by Fornell and Larcker (1981). The results for all constructs were adequate and acceptable. Composite reliability values beyond 0.70 , the Cronbach's alphas are above the 0.70 , AVE results above 0.50 as shown in Table 2, (Field, 2005; Hair et al., 2006).

In addition, the Fornell-Larcker criterion was used to measure discriminant validity by examining the crossloading comparisons between constructs. Hair et al. (2006) suggested that AVE of each latent construct should be higher than the construct's highest squared correlation with every other latent construct. Table 3 shows that this study meets this criterion.

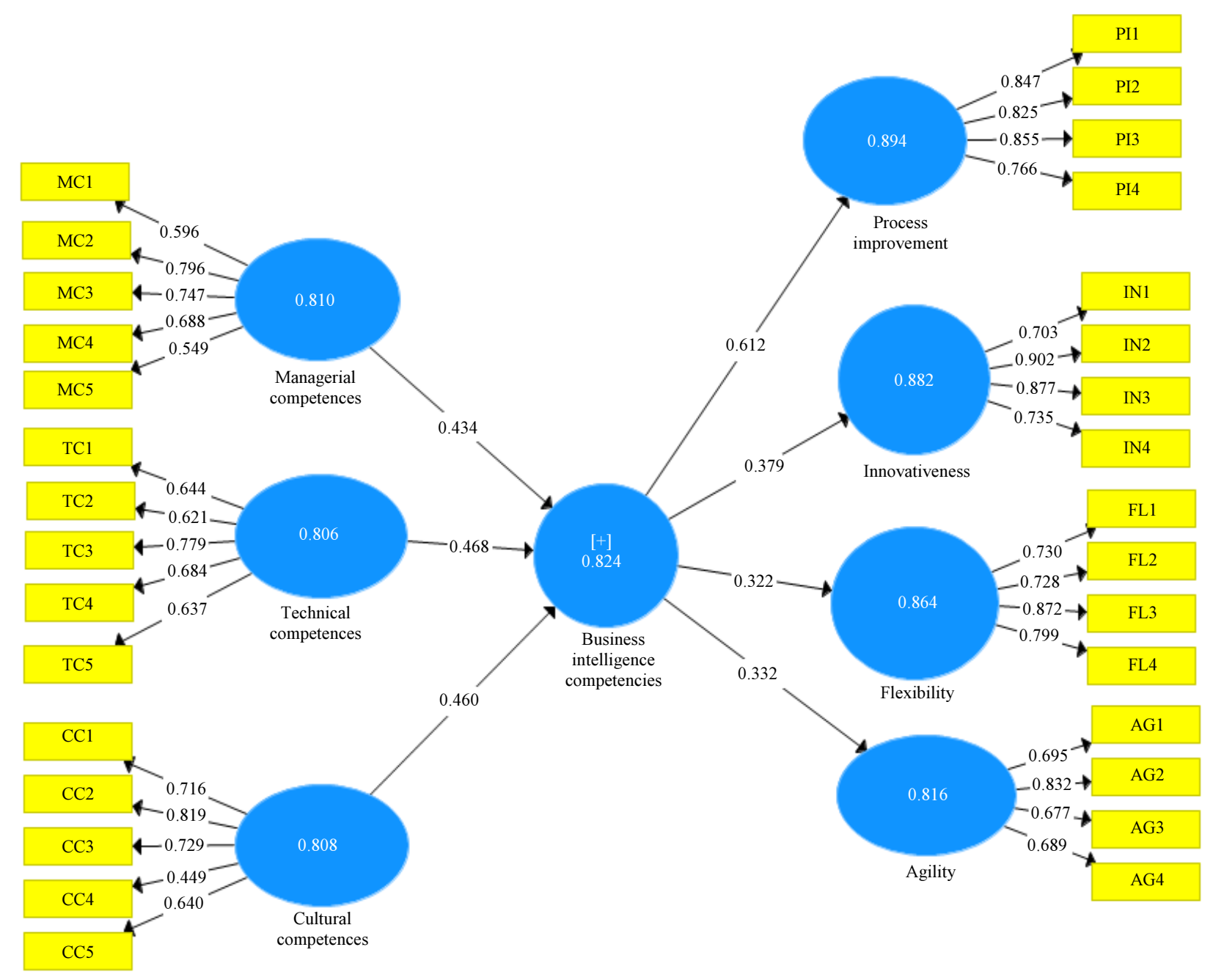

Fig. 3: Factor loading and composite reliability for each item 


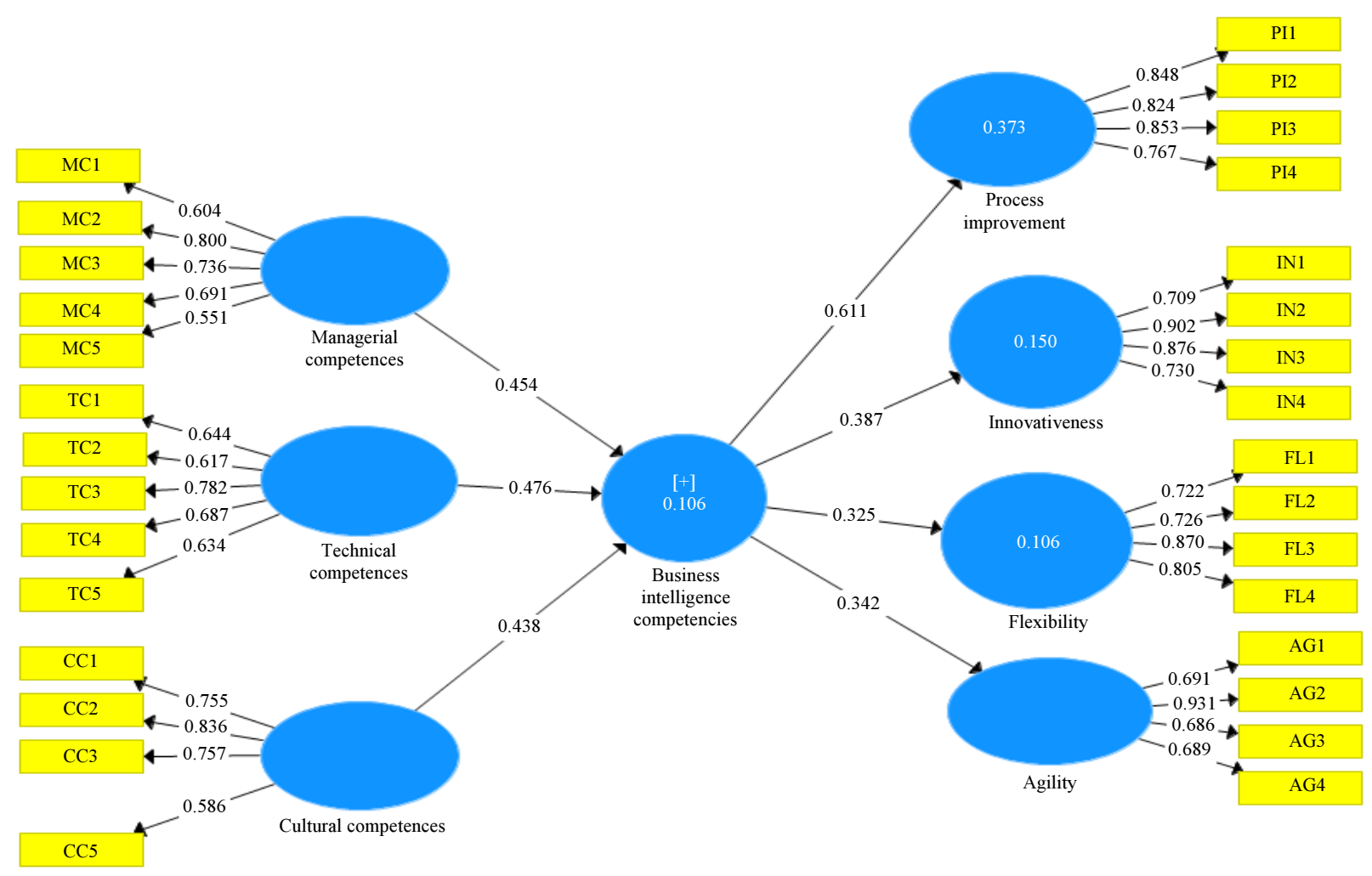

Fig. 4: The Results of the structured model

Table 2: Validity and reliability estimates of the constructs

\begin{tabular}{llll}
\hline Construct & AVE & Composite Reliability & Cronbach's Alpha \\
\hline Managerial Competences (MC) & 0.564 & 0.810 & 0.710 \\
Technical Competences (TC) & 0.556 & 0.806 & 0.701 \\
Cultural Competences (CC) & 0.565 & 0.808 & 0.707 \\
Process Improvement (PI) & 0.679 & 0.894 & 0.842 \\
Innovativeness (IN) & 0.654 & 0.882 & 0.819 \\
Flexibility (FL) & 0.616 & 0.864 & 0.799 \\
Agility (AG) & 0.527 & 0.816 & 0.711 \\
\hline
\end{tabular}

Table 3: Discriminant Validity Using Fornell and Larcker (1981) Criterion

\begin{tabular}{llllllll}
\hline Construct & AG & CC & FL & IN & MC & PI & TC \\
\hline Agility & 0.726 & & & & & & \\
Cultural Competences & 0.332 & 0.682 & & & & & \\
Flexibility & 0.488 & 0.057 & 0.785 & & & & \\
Innovativeness & 0.521 & 0.083 & 0.518 & 0.809 & 0.681 & 0.824 & \\
Managerial Competences & 0.666 & 0.069 & 0.587 & 0.628 & 0.064 & 0.558 \\
Process Improvement & 0.123 & 0.668 & 0.117 & 0.016 & 0.149 & 0.133 & \\
Technical Competences & 0.084 & 0.678 & 0.069 & & &
\end{tabular}

Assessing the Structural Model and Testing Research Hypotheses

A measurement of the structural model was conducted to find out the significance of the paths and the predictive power of the model through the PLS algorithm. The significance of path coefficients evaluated depends on the standard error, $t$-statistics, $\mathrm{R}^{2}$ value and confidence interval (Chin, 1998). $\mathrm{R}^{2}$ should be greater than 0.10 (Hair et al., 2006). Figure 4 displays the results of the structured model.

The bootstrap also was used to find out $T$ Statistics and P-value. Figure 5 shows P-values for each path. All paths are significant $(\mathrm{P}-\mathrm{value}<=0.05)$

Hypotheses testing results are shown in Table 4. All hypotheses were supported ( $\mathrm{P}$-value $<=0.05$ and $\mathrm{T}>2$ ) AS suggested by (Hair et al., 2006). 


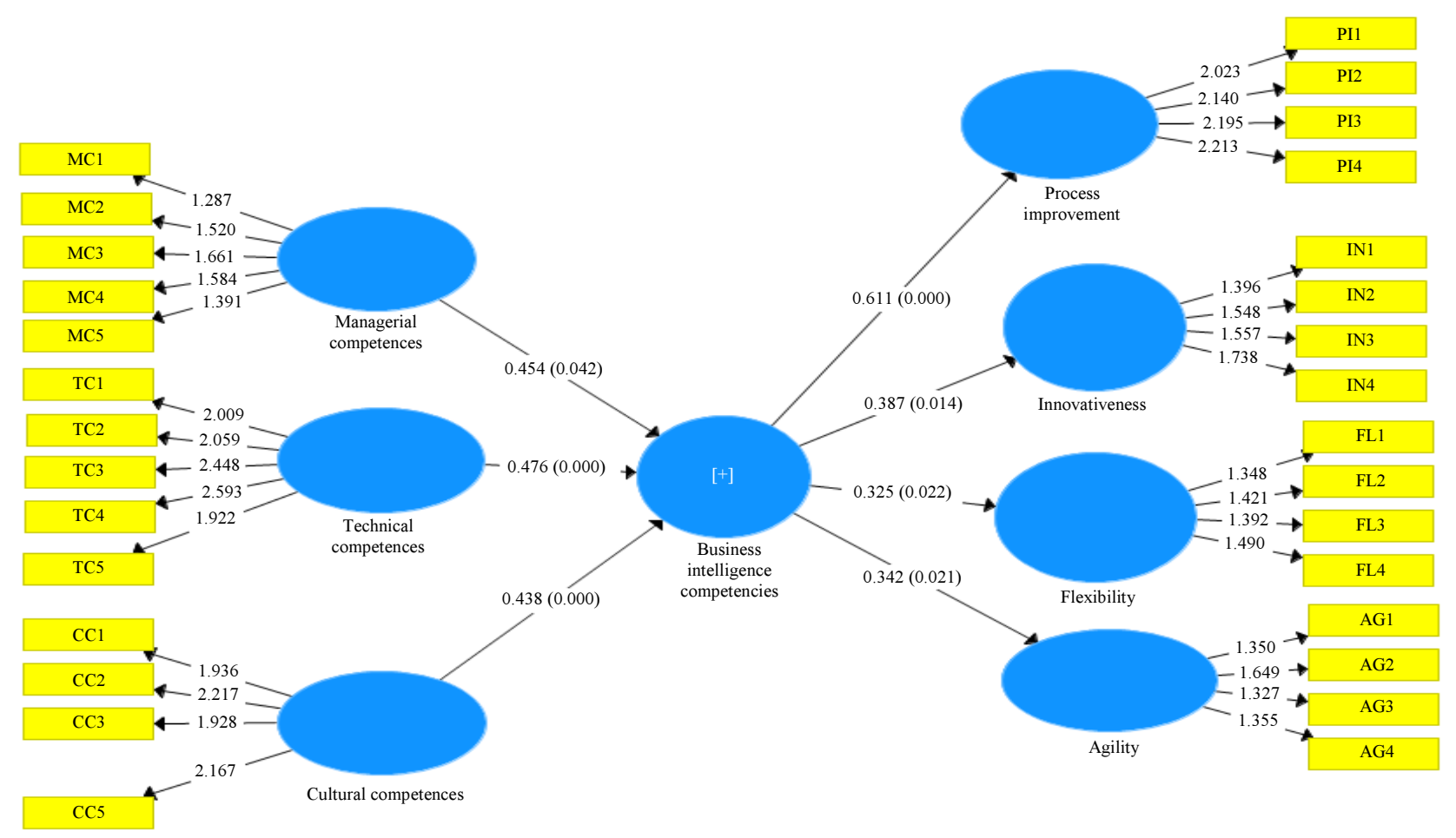

Fig. 5: Path coefficients and p-values

Table 4: The path coefficient and hypotheses results

\begin{tabular}{lllll}
\hline H\# & Path Coefficient $(\beta)$ & T Statistics & P value & The results \\
\hline H1 & $0.611^{* *}$ & 3.525 & 0.000 & Supported \\
H2 & $0.387^{* *}$ & 2.466 & 0.014 & Supported \\
H3 & $0.325^{* *}$ & 2.293 & 0.022 & Supported \\
H4 & $0.324^{* *}$ & 2.320 & 0.021 & Supported \\
\hline
\end{tabular}

\section{Result and Discussion}

Business intelligence concept is still not widespread in Jordanian business environment. Moreover, there is no deep understanding of these concepts and the requirements needed to apply these tools successfully. The purpose of this study is to give more understanding about business intelligence competences and identifying the fields where its use may be worthy. This study applies to Jordanian Banks and tries to identify to what extent are business intelligence competences available and the level of banks' capabilities accordingly (process improvement, innovation, flexibility and agility). Moreover, we seek to explore the impact of business intelligence competences on organizational capabilities. The results indicated that the level of availability of competencies was medium. The ranking was as follows: (Managerial Competences with average $=3.73$, Cultural Competences with average $=3.61$, Technical Competences with average $=3.52$ ). Based on the previous results, we realize that Jordanian banks should increase their interest in these competencies and try to enhance them, especially the technical competencies, which got the lowest average. This result is attributable to accelerated development in BI tools. Recently, software companies have provided many tools that help analyze data and identify patterns and trends for future predictions. Therefore, the banks must double their efforts to keep track of developments in this area to utilize them to offer new services. As interest in business intelligence tools and competencies will improve the work of banks such as predicting interest rates and the size of loans and will help in decisions to grant loans or not. It will also help them detect fraud and protect the cards given to customers. Also, the results indicated that the level of capabilities in Jordanian banks was medium. The rankings were as follows: (Flexibility with average $=3.90$, Agility with average $=3.67$, Process improvement $=3.61$, Innovation $=3.51)$. So, Jordanian banks should pay attention to increasing these capabilities and looking for factors that influence their improvement because improvement in these capabilities will reflect in 
improved performance, which will lead to improved and maintained competitive advantage. Moreover, we noticed that innovations got less average, therefore, it is necessary to increase attention to this variable and motivate employees and encourage them to innovate, especially those applying modern technologies need to innovate and differentiate in their use of them. The main conclusion of this study confirms that business intelligence competences have a significant impact on organizational capabilities. The values of path coefficient $(\beta)$ shows the highest impact of business intelligence competences on process improvement with $\beta=0.611$, followed by innovations, agility and flexibility, with $\beta=0.387,0.342$ and 0.325 respectively. These results are consistent with (Sangari and Razmi, 2015; GhalichKhania and Hakkakb, 2016; Golfarelli et al., 2004; Oliver, 2008; Woszczyna, 2014; Farhadfar and Abtahi, 2014; Al-ma'aitah, 2017). In addition the findings show that $(37 \%)$ of the variance in process improvement and $(15 \%)$ of the variance in innovations and $(11 \%)$ of the variance in banks agility and finally $(10 \%)$ of the variance in banks flexibility can be explained by BI competences, as shown in Fig. 4. Hence, organizations should increase their ability to produce business intelligence services and programs to use them in their decisions.

\section{Conclusion and Recommendations}

The conclusion of this study is very significant to both educational and specialist communities. This study can provide a better perspective of the role of the business intelligence competences in enhancing organizational capabilities and achieving competitive advantages. Moreover, this study show how the BI capabilities support organizational capabilities in bank sectors and provide their effectiveness to improve quality through enhance decisions. The study provides to organizations precious information and a broad picture of the impact of business intelligence competences in achieving organizational capabilities. So it will provide the practitioners with better knowledge on how to employ and control the BI systems. Further that, it will allow for enhanced planning towards BI systems adoption in the Jordanian business environment.

In the light of the previous findings of the study, the researcher made a number of recommendations as follows: To continue to pay attention to business intelligence and its capabilities because of its importance to the performance of business and organizational capabilities. Attract people with advanced knowledge in the business intelligence field, which have an important role in developing the technological infrastructure. To assess the efficiency of business intelligence competences in Jordanian banks in order to develop it in line with the changing environment and new business requirements. Spread the culture of business intelligence and incorporate it into the banks' strategies.

\section{Limitations and Future Direction of Research}

Quantitative approach was used in this study, so qualitative approach may be applied in the future for this purpose. In addition, other organizational capabilities may be added, such as marketing. Moreover, the current study did not have a chance to gather data from global organizations and all study data was collected from Jordanian banks. As a result, we are restricted in generalizing our results broadly. Finally, we recommend studying impact of business intelligence competences on achieving competitive advantages and using organizational capabilities as a mediating variable.

\section{Acknowledgment}

The Author would like to thank management of AlBalqa Applied University for encourage and motivation for me to conduct this research.

\section{Ethics}

This article is original and contains unpublished material. The corresponding author confirms that no ethical issues involved.

\section{References}

Ahmad, A., 2015. Business intelligence for sustainable competitive advantage. Adv. Bus. Market. Purchas.

Al-ma'aitah, M., 2013. The role of business intelligence tools in decision making process. Int. J. Comput. Applic., 73: 24-31.

Al-ma'aitah, M., 2017. The drivers of ERP cloud computing from an institutional perspective. J. Theoretical Applied Inform. Technol., 95: 5142-5157.

Arefin, S., R. Hoque and Y. Bao, 2015. The impact of business intelligence on organization's effectiveness: An empirical study. J. Syst. Inform. Technol., 17: 263-285. DOI: $10.1108 /$ JSIT-09-2014-0067

Carmeli, A. and A. Tishler, 2004. Resources, capabilities and the performance of industrial firms: A multivariate analysis. Managerial Decis. Econom., 25: 299-315. DOI: $10.1002 / \mathrm{mde} .1192$

Chin, W.W., 1998. The Partial Least Squares Approach for Structural Equation Modeling. In: Modern Methods for Business Research, Marcoulides, G.A. (Ed.), Lawrence Erlbaum Associates, London, pp: 295-236. 
Coronado, A.E., M. Sarhadi and C. Millar, 2002. Defining a framework for information systems requirements for agile manufacturing. Inte. J. Product. Econom., 75: 57-68. DOI: $10.1016 / \mathrm{S} 0925-5273(01) 00181-5$

Coskun, S., H. Basligil and H. Baracli, 2008. A weakness determination and analysis model for business process improvement. Bus. Process Manage. J., 14: 243-261. DOI: $10.1108 / 14637150810864961$

Cui, Z., E. Damiani and M. Leida, 2007. Benefits of ontologies in real time data access. Proceedings of the Inaugural IEEE-IES Digital EcoSystems and Technologies Conference, Feb. 21-23, IEEE Xplore Press, Cairns, Australia pp: 392-397. DOI: 10.1109/DEST.2007.372004

David, L., 2012. Business Intelligence: The Savvy Manager's Guide. Newnes, Waltham, ISBN-10: 0123858895, pp: 370.

Eicker, S., J. Kochbeck and P. Schuler, 2008. Employee competencies for business process management. Proceedings of the 11th International Conference on Business Information Systems, May 5-7, Innsbruck, Austria, pp: 251-262.

DOI: 10.1007/978-3-540-79396-0_22

Farhadfar, A. and M. Abtahi, 2014. Distinct effects of technical competence and organizational learning on organizational innovation to improve the performance of the oil and gas company. Arabian J. Bus. Manage. Rev., 4: 293-301.

Field, A., 2005. Reliability Analysis. In: Discovering Statistics Using SPSS, Field, A. (Ed.), Sage, London.

Fornell, C.G. and D.F. Larcker, 1981. Evaluating structural equation models with unobservable variables and measurement error. J. Market. Res., 18: 39-50. DOI: $10.2307 / 3151312$

GhalichKhania, R. and M. Hakkakb, 2016. A model for measuring the direct and indirect impact of business intelligence on organizational agility with partial mediatory role of empowerment (case study: Tehran construction engineering organization. Proc. Soc. Behav. Sci., 230: 413-421.

Golfarelli, M., S. Rizzi and 1. Cella, 2004. Beyond data warehousing: What's next in business intelligence? Proceedings of the ACM 7th International Workshop on Data Warehousing and OLAP, Nov. 12-13, Washington, DC, USA, pp: 1-6. DOI: $10.1145 / 1031763.1031765$

Hair, J.F., Jr, B. Black, B.J. Babin, R.E. Anderson and R.L. Tatham, 2006. Multivariate Data Analysis. 6th Edn., Prentice Hall, Upper Saddle River, NJ.

Hayen, R.L., C.D. Rutashobya and D.E. Vetter, 2007. An investigation of the factors affecting data warehousing success. Int. Assoc. Comput. Inform. Syst., 8: 547-553.
Hwang, W., 2011. The drivers of ERP implementation and its impact on organizational capabilities and performance and customer value. PhD Thesis, The University of Toledo.

Koufteros, X., 1995. Time-based competition: Developing a nomological network of constructs and instrument development. Doctoral Dissertation, University of Toledo.

Kumar, V., 2013. Data analysis using business intelligence tool. MSc Thesis, San Diego State University.

Lee, H.L., 2004. The triple-a supply chain. Harvard Bus. Rev., 82: 102-112.

Löfsten, H., 2016. Organizational capabilities and the long-term survival of new technology-based firms. Eur. Bus. Rev., 28: 312-332. DOI: 10.1108/EBR-04-2015-0041

Lonnqvist, A. and V. Pirttimaki, 2006. The measurement of business intelligence. Inform. Syst. Manage., 23: 32-40. DOI: $10.1201 / 1078.10580530 / 45769.23 .1 .20061201 / 917$ 70.4

Machuca, M.M. and C.M. Costa, 2012. A study of knowledge culture in the consulting industry. Indus. Manage. Data Syst., 112: 24-41. DOI: $10.1108 / 02635571211193626$

McGrath, R., 2001. Exploratory learning, innovative capacity and managerial oversight. Acad. Manage. J., 44: 118-131. DOI: 10.2307/3069340

Muhammad, G., Z. Bhatti, J. Ibraham and A. Wages, 2014. Business intelligence as a knowledge management tool in providing financial consultancy services. Am. J. Inform. Syst., 2: 26-32. DOI: 10.12691/ajis-2-2-1

Narasimhan, R., S. Talluri and A. Das, 2004. Exploring flexibility and execution competencies of manufacturing firms. J. Operat. Manage., 22: 91-106. DOI: 10.1016/j.jom.2003.12.003

Ngo, H.Y. and R. Loi, 2008. Human resource flexibility, organizational culture and firm performance: An investigation of multinational firms in Hong Kong. Int. J. Human Resource Manage., 19: 1654-1666.

Oliver, G., 2008. Information culture: Exploration of differing values and attitudes to information in organizations. J. Document., 64: 363-385. DOI: $10.1108 / 00220410810867588$

Olszak, C. and E. Ziemba, 2007. Approach to building and implementing business intelligence systems. Interdisciplinary J. Inform. Knowl. Manage., 2: 135-148.

Olszak, C.M. and E. Ziemba, 2004. Business intelligence systems as a new generation of decision support systems. Proceedings PISTA International Conference on Politics and Information Systems: Technologies and Applications. Orlando: The International Institute of Informatics and Systemics. 
Pandey, S., A. Dutta and A. Nayak, 2018. Organizational capabilities and knowledge management success: A quartet of case studies. Kybernetes, 47: 222-238. DOI: $10.1108 / \mathrm{K}-01-2017-0041$

Petrini, M. and M. Pozzebon, 2009. Managing sustainability with the support of business intelligence: Integrating socio-environmental indicators and organizational context. J. Strategic Inform. Syst., 18: 178-191. DOI: $10.1016 /$ j.jsis.2009.06.001

Rahman, M. and C. Carpano, 2017. National corporate social policy, corporate governance systems and organizational capabilities. Corporate Governance: Int. J. Bus. Society, 17: 13-29.

DOI: 10.1108/CG-02-2016-0037

Ramakrishnan, T., M.C. Jones and A. Sidorova, 2012. Factors influencing Business Intelligence (BI) data collection strategies: an empirical investigation. Decis. Support Syst., 52: 486-496. DOI: $10.1016 /$ j.dss.2011.10.009

Ramamurthy, K., A. Sen and A.P. Sinha, 2008. An empirical investigation of the key deter-minants of data warehouse adoption. Decis. Support Syst., 44: 817-841. DOI: 10.1016/j.dss.2007.10.006

Ravichandran, T. and A. Rai, 2000. Quality management in systems development: An organizational system perspective. MIS Q., 24: 381-415. DOI: $10.2307 / 3250967$

Rouhani, S., A. Ashrafi, A. Ravasan and S. Afshari, 2016. The impact model of business intelligence on decision support and organizational benefits. J. Enterprise Inform. Manage., 29: 19-50. DOI: 10.1108/JEIM-12-2014-0126

Sanchez, R., 1995. Strategic flexibility in product competition. Strategic Manage. J., 16: 135-159. DOI: $10.1002 / \mathrm{smj} .4250160921$

Sangari, M. and J. Razmi, 2015. Business intelligence competence, agile capabilities and agile performance in supply chain: An empirical study. Logist. Manage., 26: 356-380.

DOI: 10.1108/IJLM-01-2013-0012
Tellez, T., 2015. Culturally effective healthcare organizations: A framework for success. Brandeis University, Waltham, MA.

Temtime, Z. and J. Pansiri, 2005. Managerial competency and organizational flexibility in small and medium enterprises in Botswana. Problems Perspect. Manage., 3: 25-36.

Tuan, N. and Y. Takahasi, 2010. Organizational capabilities, competitive advantage and performance in supporting industries in Vietnam. Asian Acad. Manage. J., 15: 1-21.

Turban, E., 2010. Electronic Commerce: A Managerial Perspective. 6th Edn., Pearson/Prentice Hall, ISBN10: 8131724786, pp: 832.

Verona, G., 1999. A resource-based view of product development. Acad. Manage. Rev., 24: 132-42. DOI: $10.5465 / \mathrm{amr}$. 1999.1580445

Wang, C.K. and B.L. Ang, 2004. Determinants of venture performance in Singapore. J. Small Bus. Manage., 42: 347-363. DOI: $10.1111 / \mathrm{j} .1540-627 X .2004 .00116 . \mathrm{X}$

White, C., 2006. A process-centric approach to business intelligence. Data Min. Rev., 16: 14-18.

Williams, S. and N. Williams, 2007. The Profit Impact of Business Intelligence. 1st Edn., Elsevier Inc., San Francisco, ISBN-10: 0123706432, pp: 218.

Woszczyna, K., 2014. The importance of organizational culture for innovation in the company. Forum Scientiae Oeconomia, 2: 27-39.

Zabadi, A., M. Alshura and A. Rahim, 2015. Impact of business intelligence on employee knowledge sharing in Jordanian telecommunication company. Int. J. Educ.

\section{Source of Figures}

Fig. 1: Source: Muhammad et al. (2014), Business Intelligence as a Knowledge Management Tool in Providing Financial Consultancy Services, American Journal of Information Systems, Vol. 2, No. 2, 26-32. 